\title{
Prevalence of onychophagia and its relation to stress and quality of life
}

\author{
Hilal Kaya Erdogan ${ }^{1 凶}$, Didem Arslantas², Emrah Atay², Damla Eyuboglu³, Alaettin Unsal², Gokce Dagtekin², Ali Kilinc ${ }^{2}$ \\ ${ }^{1}$ Department of Dermatology, Faculty of Medicine, Eskişehir Osmangazi University, Eskişehir, Turkey. ${ }^{2}$ Department of Public Health, Faculty of Medicine, \\ Eskişehir Osmangazi University, Eskişehir, Turkey. ${ }^{3}$ Department of Child and Adolescent Psychiatry, Faculty of Medicine, Eskişehir Osmangazi \\ University, Eskişehir, Turkey.
}

\begin{abstract}
Introduction: Onychophagia is defined as putting one's fingers into the mouth and biting the nails. We sought to evaluate the prevalence of onychophagia in university and high school students and its relation to sociodemographic factors, perceived stress, and quality of life.

Methods: A total of 3,475 students were included in the study. A questionnaire including sociodemographic characteristics, items about onychophagia, the Perceived Stress Scale (PSS), and the European Health Impact Scale was used.

Results: The prevalence of onychophagia among university students was $17.6 \%$, and among high school students it was $29.2 \%$. In university students with onychophagia, the median score on the PSS was higher than the median score of students without onychophagia. In high school students, the median score on the PSS was 28.2 for students without onychophagia and 28.0 for students with onychophagia; the difference was not significant. The median scores on the quality of life scale for both university and high school students with onychophagia were lower than the mean score of students without onychophagia.

Conclusions: Onychophagia is a common problem in the general population with a multidimensional etiology. It has dermatological, dental, and psychiatric consequences and comorbidities, and so a multidisciplinary approach is necessary for the prevention and treatment of onychophagia.
\end{abstract}

Keywords: onychophagia, nail-biting, quality of life, stress

Received: 17 August 2020 | Returned for modification: 11 December 2020 | Accepted: 6 January 2021

\section{Introduction}

Onychophagia, or nail-biting, is defined as putting one's fingers into the mouth and biting the nails. It usually starts in childhood, after 3 to 4 years of age, and may continue into adulthood. It may be a patient's chief complaint, but it is more commonly detected incidentally, and so the incidence is underestimated (1-4).

The etiology of onychophagia is not precisely known; genetic, familial, and psychiatric factors are blamed. Onychophagia is mostly an automatic behavior. However, in some people, onychophagia may be an intentional activity, the result of a desire to have perfect nails. They reveal biting their nails to correct irregularities of the nails (5). Psychiatric disorders, such as anxiety and obsessive-compulsive disorder (OCD), usually accompany onychophagia. Moreover, in the Diagnostic and Statistical Manual of Mental Disorders, Fifth Edition (DSM-V), onychophagia is classified among other specified obsessive-compulsive and related disorders, as a body-focused repetitive behavior (1-3).

It is sometimes thought that onychophagia is merely a habit and causes cosmetic problems; however, numerous complications can be seen. Nail, cuticle, gingival, dental, and temporomandibular joint problems and infections are more common in patients with onychophagia (6-8).

Most studies of onychophagia have been conducted on children (9-11). There are limited data related to the prevalence of onychophagia in adolescents and young adults, and its relation to stress and quality of life. Onychophagia is a public health problem in terms of both frequency and health outcomes, and so it is important to present the current status of the disease to plan, deliver, and monitor health services for onychophagia. The aim of this study was to evaluate the prevalence of onychophagia in universi- ty and high school students, and its relation to sociodemographic factors, perceived stress, and quality of life.

\section{Materials and methods}

This cross-sectional study was conducted between March and June 2019 among high school and university students in Turkey's Eskişehir Province.

The study protocol was approved by the local ethics committee. Written permissions were obtained from the Eskisehir Provincial Directorate of National Education and Eskişehir Osmangazi University. Informed consent was obtained from all participants.

High schools in Eskişehir were socioeconomically classified as low, medium, and high based on the status of territories that surround them. The minimum sample size was calculated as 384 people with the following criteria: 95\% confidence interval, $5 \%$ type 1 error, $5 \%$ acceptable margin of error, and assuming that the prevalence of onychophagia is $50 \%$. Two high schools were chosen randomly from each region. Two schools were randomly selected for each region, and it was planned to reach 200 students per school (a total of 400 students per region). Thus, the aim was to reach at least 1,200 high school students for three different regions. For university students, the sample size was calculated as a minimum of 384 people for each faculty, at least 1,540 students in total, based on a $95 \%$ confidence interval and $5 \%$ error margin, assuming $50 \%$ frequency of onychophagia. The study group consisted of 3,475 students, of whom 1,471 (42.3\%) were high school students and 2,004 (57.7\%) were university students. Students' family income status was labeled as low, medium, and high based on the students' perceptions.

Data collection was performed in classes of students on days 
and at hours that were appropriate according to the administration of the schools and faculties. The students were informed and verbal consent was obtained. The questionnaires were filled out by the students themselves under the observation of the researchers. This process took about 10 to 15 minutes. Students that refused to participate in the study, 12th-grade students from high schools, and those that were not at school on a school day were not included in the study.

In this study, a questionnaire consisting of four sections was prepared with the guidance of literature $(3,5,9)$. The first part of the questionnaire consisted of items about students' sociodemographics, the second part included items about onychophagia characteristics, the third part consisted of items on the Perceived Stress Scale (PSS), and the fourth part consisted of questions from the European Health Impact Scale (EUROHISQOL-8).

The PSS was used to evaluate the students' stress levels. It was developed by Cohen and Mermelstein in 1983 (12). The reliability and validity of the Turkish version were verified by Eskin et al. It has 14 items and was designed to measure how stressful an individual's life situations is perceived to be. The total score on the scale ranges between 0 and 56. As the score obtained from the scale increases, perceived stress levels increase (13). To assess the quality of life, EUROHISQOL-8, a short form derived from the World Health Organization Quality of Life Scale (WHOQOL), was used. The reliability and validity of the scale for the Turkish population were verified by Eser et al. The scale consists of eight questions, and the quality of life improves as the score on the scale increases (14).

\section{Statistical analysis}

Analyses were performed using the software program SPSS Statistics v15 (Chicago, Illinois). Continuous data were presented as mean \pm standard deviation. Categorical data were presented in percentage $(\%)$ values. Normality was analyzed using the Shapiro-Wilk test. The chi-squared test, Mann-Whitney $U$ test, Kruskal-Wallis $H$ test, and Spearman correlation analysis were performed for the analyzes. It is considered significant if the $p$ value $<0.05$.

\section{Results}

A total of 3,475 students, 2,004 (57.7\%) university students and $1,471(42.3 \%)$ high school students, were included in the study. Of these, 792 (39.5\%) university students and 865 (58.8\%) high school students were male. The mean age of the university students was $20.65 \pm 2.02$ years (range $17-40$ years), and the mean age of the high school students was $15.6 \pm 0.98$ years (range 14-20 years). The frequency of onychophagia among university students was $17.6 \%(n=352)$ and $29.2 \%(n=429)$ in high school students, and the difference was significant $(p \leq 0.05)$. The distribution of the students with and without onychophagia according to their educational status and sociodemographic characteristics is given in Table 1.

In university students, the frequency of onychophagia was found to be higher in students with histories of mental disorder, chronic disease, onychophagia, nail infection, jaw pain, and family histories of chronic disease, mental disorder, and onychophagia. In high school students, the frequency of onychophagia was found to be higher in students with histories of jaw pain, onychophagia, nail infection, and a family history of onychophagia (Ta- ble 2).

Considering the prevalence of onychophagia, $43.0 \%$ of university students and $67.7 \%$ of high school students revealed that they bit their nails 1 to 2 days per week. Health problems due to onychophagia were not seen in most of the students. Both university $(54.1 \%)$ and high school students (50.6\%) revealed that they felt relaxed after biting their nails. Most of the university and high school students with onychophagia did not believe that this harmed their reputation, set a bad example for others, or caused a negative reaction from people. Although most of the university students needed to hide their onychophagia (56.6\%), high school students did not (55.9\%). Stress was the most common situation associated with onychophagia in both university (61.7\%) and high school students $(43.7 \%)$. Onychophagia was not accompanied by any behavior in most of the students. The most common accompanying behavior was lip and cheek biting in both university (24.2\%) and high school students (13.7\%). The distribution of university and high school students with onychophagia by certain attitudes, behaviors, and situations is given in Table 3 .

In university students, the median score on the PSS was 28.0 (range 2.0-53.0) for students without onychophagia and 29.0 (range 5.0-51.0) for students with onychophagia. The median score for university students with onychophagia was higher than the mean score of students without onychophagia, and the difference was significant $(p=0.001)$. The median score on the quality of life scale for university students with onychophagia was 26.0 (range 8.0-40.0) and 28.0 (range 8.0-40.0) for those without onychophagia. The median score for university students with onychophagia was lower than the mean score of students without onychophagia, and the difference was significant $(p<0.001)$. In high school students, the median score on the PSS was 28.2 (range 4.0-54.0) for students without onychophagia and 28.0 (range 2.0-53.0) for students with onychophagia; the difference was not significant. The median score on the quality of life scale for high school students without onychophagia was 29.0 (range 8.0-40.0) and 28.0 (range 8.0-40.0) for those with onychophagia. The median score for the high school students with onychophagia was lower than the mean score of students without onychophagia, and the difference was significant ( $p=0.001$; Table 4 ).

\section{Discussion}

Onychophagia is an important public health problem because it is common in the general population. Its prevalence is in fact underestimated because patients may hide onychophagia and avoid seeing a doctor due to embarrassment (1). Garde et al. found onychophagia in $5.8 \%$ of 6 - to 12 -year-old Indian children (15). Ghanizadeh et al. found that $22.3 \%$ of 7 - to 10 -year-old children had onychophagia in Iran (11). In the United States, the prevalence of nail-biting was found to be $37 \%$ in people 3 to 21 years old in an urban setting (9). In a study from Poland, the frequency of onychophagia among university students (21-26 years old) was found to be as high as $46.9 \%$ (16). In our study, the frequency of onychophagia was $17.6 \%$ in university students and $29.2 \%$ in high school students; this is consistent with the literature, in which the prevalence decreases with age $(9,16)$. Differences in the prevalence of onychophagia between studies from different countries may result from ethnic and sociocultural differences between the populations or methodological differences between the studies.

Garde et al. found that onychophagia was more common among girls (15). In our study, onychophagia was more common 
Table 1 | Distribution of students without and with onychophagia by characteristics.

\begin{tabular}{|c|c|c|c|c|c|c|c|c|c|}
\hline \multirow{3}{*}{ Characteristic } & & \multicolumn{4}{|c|}{ University } & \multicolumn{4}{|c|}{ High school } \\
\hline & & \multicolumn{4}{|c|}{$n(\%)$} & \multicolumn{4}{|c|}{$n(\%)$} \\
\hline & & Without* & With* & Total** & $p$ & Without* & With* & Total** & $p$ \\
\hline \multirow[t]{2}{*}{ Sex } & Male & $\begin{array}{c}644 \\
(81.4)\end{array}$ & $\begin{array}{c}147 \\
(18.6)\end{array}$ & $\begin{array}{c}791 \\
(39.5)\end{array}$ & \multirow[t]{2}{*}{0.093} & $\begin{array}{c}628 \\
(72.8)\end{array}$ & $\begin{array}{c}235 \\
(27.2)\end{array}$ & $\begin{array}{c}863 \\
(58.7)\end{array}$ & \multirow[t]{2}{*}{0.047} \\
\hline & Female & $\begin{array}{l}1,008 \\
(83.1)\end{array}$ & $\begin{array}{c}205 \\
(16.9)\end{array}$ & $\begin{array}{l}1,213 \\
(60.5)\end{array}$ & & $\begin{array}{c}412 \\
(68.0)\end{array}$ & $\begin{array}{c}194 \\
(32.0)\end{array}$ & $\begin{array}{c}606 \\
(41.3)\end{array}$ & \\
\hline \multirow[t]{3}{*}{ Family income } & Low & $\begin{array}{c}78 \\
(77.2)\end{array}$ & $\begin{array}{c}23 \\
(22.8)\end{array}$ & $\begin{array}{c}101 \\
(5.0)\end{array}$ & \multirow[t]{3}{*}{0.205} & $\begin{array}{c}49 \\
(77.8)\end{array}$ & $\begin{array}{c}14 \\
(22.2)\end{array}$ & $\begin{array}{c}63 \\
(4.3)\end{array}$ & \multirow[t]{3}{*}{0.458} \\
\hline & Medium & $\begin{array}{l}1,426 \\
(83.1)\end{array}$ & $\begin{array}{c}291 \\
(16.9)\end{array}$ & $\begin{array}{l}1,717 \\
(85.8)\end{array}$ & & $\begin{array}{c}852 \\
(70.5)\end{array}$ & $\begin{array}{c}356 \\
(29.5)\end{array}$ & $\begin{array}{l}1,208 \\
(82.2)\end{array}$ & \\
\hline & High & $\begin{array}{c}147 \\
(79.9)\end{array}$ & $\begin{array}{c}37 \\
(20.1)\end{array}$ & $\begin{array}{c}184 \\
(9.2)\end{array}$ & & $\begin{array}{c}139 \\
(70.2)\end{array}$ & $\begin{array}{c}59 \\
(29.8)\end{array}$ & $\begin{array}{c}198 \\
(13.5)\end{array}$ & \\
\hline \multirow[t]{2}{*}{ Maternal education } & $\leq$ Secondary & $\begin{array}{c}915 \\
(82.5)\end{array}$ & $\begin{array}{c}194 \\
(17.5)\end{array}$ & $\begin{array}{l}1,109 \\
(55.3)\end{array}$ & \multirow[t]{2}{*}{0.925} & $\begin{array}{c}474 \\
(73.5) \\
\end{array}$ & $\begin{array}{c}171 \\
(26.5)\end{array}$ & $\begin{array}{c}645 \\
(43.9)\end{array}$ & \multirow[t]{2}{*}{0.045} \\
\hline & $\geq$ High school & $\begin{array}{c}737 \\
(82.3)\end{array}$ & $\begin{array}{c}158 \\
(17.7)\end{array}$ & $\begin{array}{c}895 \\
(44.7)\end{array}$ & & $\begin{array}{c}566 \\
(68.7)\end{array}$ & $\begin{array}{c}258 \\
(31.3)\end{array}$ & $\begin{array}{c}824 \\
(56.1)\end{array}$ & \\
\hline \multirow[t]{2}{*}{ Paternal education } & $\leq$ Secondary & $\begin{array}{c}611 \\
(82.9)\end{array}$ & $\begin{array}{c}126 \\
(17.1)\end{array}$ & $\begin{array}{c}737 \\
(36.8)\end{array}$ & & $\begin{array}{c}277 \\
(69.8)\end{array}$ & $\begin{array}{c}120 \\
(30.2)\end{array}$ & $\begin{array}{c}397 \\
(27.0)\end{array}$ & \multirow[t]{2}{*}{0.582} \\
\hline & $\geq$ High school & $\begin{array}{l}1,040 \\
(82.1)\end{array}$ & $\begin{array}{c}226 \\
(17.9)\end{array}$ & $\begin{array}{l}1,266 \\
(63.2)\end{array}$ & & $\begin{array}{c}763 \\
(71.2)\end{array}$ & $\begin{array}{c}308 \\
(28.8)\end{array}$ & $\begin{array}{l}1,071 \\
(73.0)\end{array}$ & \\
\hline \multirow[t]{2}{*}{ Alcohol consumption } & No & $\begin{array}{l}1,227 \\
(82.8)\end{array}$ & $\begin{array}{c}254 \\
(17.2)\end{array}$ & $\begin{array}{l}1,481 \\
(74.8)\end{array}$ & \multirow[t]{2}{*}{0.593} & & & & \\
\hline & Yes & $\begin{array}{c}409 \\
(81.8)\end{array}$ & $\begin{array}{c}91 \\
(18.2)\end{array}$ & $\begin{array}{c}500 \\
(25.2)\end{array}$ & & & & & \\
\hline \multirow[t]{2}{*}{ Smoking } & No & $\begin{array}{l}1,181 \\
(84.1)\end{array}$ & $\begin{array}{c}224 \\
(15.9)\end{array}$ & $\begin{array}{l}1,405 \\
(70.4)\end{array}$ & \multirow[t]{2}{*}{0.005} & & & & \\
\hline & Yes & $\begin{array}{c}466 \\
(78.8)\end{array}$ & $\begin{array}{c}125 \\
(21.2)\end{array}$ & $\begin{array}{c}591 \\
(29.6)\end{array}$ & & & & & \\
\hline
\end{tabular}

*Percentage of rows.

$\star \star$ Percentage of columns.

Table 2 | Distribution of students without and with onychophagia by medical and family histories.

\begin{tabular}{|c|c|c|c|c|c|c|c|c|c|}
\hline \multirow{3}{*}{ Associated factors } & & \multicolumn{4}{|c|}{ University } & \multicolumn{4}{|c|}{ High school } \\
\hline & & \multicolumn{4}{|c|}{$n(\%)$} & \multicolumn{4}{|c|}{$n(\%)$} \\
\hline & & Without* & With* & Total** & $p$ & Without* & With* & Total** & $p$ \\
\hline \multirow[t]{2}{*}{ History of chronic disease } & No & $\begin{array}{l}1,530 \\
(83.2)\end{array}$ & $\begin{array}{c}308 \\
(16.8)\end{array}$ & $\begin{array}{l}1,838 \\
(92.8)\end{array}$ & $<0.001$ & $\begin{array}{c}523 \\
(69.3)\end{array}$ & $\begin{array}{c}232 \\
(30.7)\end{array}$ & $\begin{array}{c}755 \\
(90.3)\end{array}$ & 0.630 \\
\hline & Yes & $\begin{array}{c}103 \\
(72.5)\end{array}$ & $\begin{array}{c}39 \\
(27.5)\end{array}$ & $\begin{array}{l}142 \\
(7.2)\end{array}$ & & $\begin{array}{c}54 \\
(66.7)\end{array}$ & $\begin{array}{c}27 \\
(33.3)\end{array}$ & $\begin{array}{c}81 \\
(9.7)\end{array}$ & \\
\hline \multirow[t]{2}{*}{$\begin{array}{l}\text { Family history of chronic } \\
\text { disease }\end{array}$} & No & $\begin{array}{l}1,167 \\
(84.0)\end{array}$ & $\begin{array}{c}223 \\
(16.0)\end{array}$ & $\begin{array}{l}1,390 \\
(72.1)\end{array}$ & 0.006 & $\begin{array}{c}434 \\
(69.2)\end{array}$ & $\begin{array}{c}193 \\
(30.8)\end{array}$ & $\begin{array}{c}627 \\
(74.9)\end{array}$ & 0.761 \\
\hline & Yes & $\begin{array}{c}423 \\
(78.6)\end{array}$ & $\begin{array}{c}115 \\
(21.4)\end{array}$ & $\begin{array}{c}538 \\
(27.9)\end{array}$ & & $\begin{array}{c}143 \\
(68.1)\end{array}$ & $\begin{array}{c}67 \\
(31.9)\end{array}$ & $\begin{array}{c}210 \\
(25.1)\end{array}$ & \\
\hline \multirow[t]{2}{*}{$\begin{array}{l}\text { Medical history of } \\
\text { onychophagia }\end{array}$} & No & $\begin{array}{l}1,393 \\
(96.4)\end{array}$ & $\begin{array}{c}52 \\
(3.6)\end{array}$ & $\begin{array}{l}1,445 \\
(72.2)\end{array}$ & $<0.001$ & $\begin{array}{c}866 \\
(83.2)\end{array}$ & $\begin{array}{c}175 \\
(16.8)\end{array}$ & $\begin{array}{l}1,041 \\
(70.9)\end{array}$ & $<0.001$ \\
\hline & Yes & $\begin{array}{c}258 \\
(46.4)\end{array}$ & $\begin{array}{c}298 \\
(53.6)\end{array}$ & $\begin{array}{c}556 \\
(27.8)\end{array}$ & & $\begin{array}{c}174 \\
(40.7)\end{array}$ & $\begin{array}{c}253 \\
(59.3)\end{array}$ & $\begin{array}{c}427 \\
(29.1)\end{array}$ & \\
\hline \multirow[t]{2}{*}{$\begin{array}{l}\text { Medical history of mental } \\
\text { disorder }\end{array}$} & No & $\begin{array}{l}1,548 \\
(83.6)\end{array}$ & $\begin{array}{c}303 \\
(16.4)\end{array}$ & $\begin{array}{l}1,851 \\
(92.5)\end{array}$ & $<0.001$ & $\begin{array}{c}969 \\
(71.3)\end{array}$ & $\begin{array}{c}390 \\
(28.7)\end{array}$ & $\begin{array}{l}1,359 \\
(92.5)\end{array}$ & 0.134 \\
\hline & Yes & $\begin{array}{c}102 \\
(67.5)\end{array}$ & $\begin{array}{c}49 \\
(32.5)\end{array}$ & $\begin{array}{l}151 \\
(7.5)\end{array}$ & & $\begin{array}{c}71 \\
(64.5)\end{array}$ & $\begin{array}{c}39 \\
(35.5)\end{array}$ & $\begin{array}{c}110 \\
(7.5)\end{array}$ & \\
\hline \multirow[t]{2}{*}{$\begin{array}{l}\text { Family history of mental } \\
\text { disorder }\end{array}$} & No & $\begin{array}{l}1,514 \\
(83.7)\end{array}$ & $\begin{array}{c}294 \\
(16.3)\end{array}$ & $\begin{array}{l}1,808 \\
(90.4)\end{array}$ & $<0.001$ & $\begin{array}{c}910 \\
(70.7)\end{array}$ & $\begin{array}{c}378 \\
(29.3)\end{array}$ & $\begin{array}{l}1,288 \\
(87.7)\end{array}$ & 0.746 \\
\hline & Yes & $\begin{array}{c}135 \\
(70.3)\end{array}$ & $\begin{array}{c}57 \\
(29.7)\end{array}$ & $\begin{array}{l}192 \\
(9.6)\end{array}$ & & $\begin{array}{c}130 \\
(71.8)\end{array}$ & $\begin{array}{c}51 \\
(28.8)\end{array}$ & $\begin{array}{c}181 \\
(12.3)\end{array}$ & \\
\hline \multirow[t]{2}{*}{ Jaw pain } & No & $\begin{array}{l}1,216 \\
(84.3)\end{array}$ & $\begin{array}{c}227 \\
(15.7)\end{array}$ & $\begin{array}{l}1,443 \\
(72.0)\end{array}$ & $<0.001$ & $\begin{array}{c}455 \\
(71.4)\end{array}$ & $\begin{array}{c}182 \\
(28.6)\end{array}$ & $\begin{array}{c}637 \\
(76.2)\end{array}$ & 0.005 \\
\hline & Yes & $\begin{array}{c}435 \\
(77.7)\end{array}$ & $\begin{array}{c}125 \\
(22.3)\end{array}$ & $\begin{array}{c}560 \\
(28.0)\end{array}$ & & $\begin{array}{c}121 \\
(60.8)\end{array}$ & $\begin{array}{c}78 \\
(39.2)\end{array}$ & $\begin{array}{c}199 \\
(23.8)\end{array}$ & \\
\hline \multirow[t]{2}{*}{$\begin{array}{l}\text { Family history of } \\
\text { onychophagia }\end{array}$} & No & $\begin{array}{l}1,419 \\
(86.4)\end{array}$ & $\begin{array}{c}223 \\
(13.6)\end{array}$ & $\begin{array}{l}1,642 \\
(81.9)\end{array}$ & $<0.001$ & $\begin{array}{c}785 \\
(73.8)\end{array}$ & $\begin{array}{c}279 \\
(26.2)\end{array}$ & $\begin{array}{l}1,064 \\
(72.4)\end{array}$ & $<0.001$ \\
\hline & Yes & $\begin{array}{c}233 \\
(64.4)\end{array}$ & $\begin{array}{c}129 \\
(35.6)\end{array}$ & $\begin{array}{c}362 \\
(18.1)\end{array}$ & & $\begin{array}{c}255 \\
(63.0) \\
\end{array}$ & $\begin{array}{c}150 \\
(37.0)\end{array}$ & $\begin{array}{c}405 \\
(27.6)\end{array}$ & \\
\hline \multirow[t]{2}{*}{$\begin{array}{l}\text { Medical history of nail } \\
\text { infection }\end{array}$} & No & $\begin{array}{l}1,542 \\
(83.1)\end{array}$ & $\begin{array}{c}313 \\
(16.9)\end{array}$ & $\begin{array}{l}1,855 \\
(92.6)\end{array}$ & 0.004 & $\begin{array}{c}891 \\
(72.1)\end{array}$ & $\begin{array}{c}344 \\
(27.9)\end{array}$ & $\begin{array}{l}1,235 \\
(84.1)\end{array}$ & 0.012 \\
\hline & Yes & $\begin{array}{c}110 \\
(73.8)\end{array}$ & $\begin{array}{c}39 \\
(26.2)\end{array}$ & $\begin{array}{l}149 \\
(7.4) \\
\end{array}$ & & $\begin{array}{c}149 \\
(63.9)\end{array}$ & $\begin{array}{c}84 \\
(36.1)\end{array}$ & $\begin{array}{c}233 \\
(15.9)\end{array}$ & \\
\hline
\end{tabular}


in high school girls, but there was no significant sex difference among university students. There are also studies revealing no difference in the frequency of onychophagia between girls and boys $(9,11,16)$. A positive family history for onychophagia is important in terms of a genetic basis, and imitation of parental behavior is a possible etiological factor for onychophagia. In our study, students with onychophagia had higher percentages of positive family history for onychophagia than students without onychophagia. Furthermore, we found that smoking was more prevalent among university students with onychophagia. No other study evaluates the relationship between smoking and onychophagia. A high prevalence of smoking in students with onychophagia may be associated with stress or imitation of family member behavior similar to onychophagia.

Oral habits are recurrent, harmful, parafunctional behaviors in the oral cavity resulting in impairment of the stomatognathic system and quality of life. These are nail-biting, tongue thrusting, lip biting/sucking, pencil biting, cheek biting, digit sucking, bruxism, pacifier sucking, bottle feeding, and mouth breathing $(15,17)$. Garde et al. found at least one oral habit in $51.1 \%$ of 6 - to 12-year-old children. Bruxism was reported as the most common habit, followed by bottle feeding, thumb sucking, nail-biting, tongue thrusting, and mouth breathing (15). Hegde et al. reported that $19.9 \%$ of children ( 4 to 15 years old) had adverse oral habits.

Table 3 | Distribution of university and high school students with onychophagia by attitudes, behaviors, and situations.

\begin{tabular}{|c|c|c|c|}
\hline \multirow{2}{*}{ Characteristics } & & \multicolumn{2}{|c|}{$n(\%)$} \\
\hline & & University & High school \\
\hline \multirow{7}{*}{$\begin{array}{l}\text { Days with } \\
\text { onychophagia } \\
\text { per week }\end{array}$} & 1 & $90(21.5)$ & $634(67.3)$ \\
\hline & 2 & $90(21.5)$ & $98(10.4)$ \\
\hline & 3 & $62(14.8)$ & $50(5.3)$ \\
\hline & 4 & $42(10.0)$ & $30(3.2)$ \\
\hline & 5 & $28(6.7)$ & $29(3.1)$ \\
\hline & 6 & $12(2.9)$ & $5(0.5)$ \\
\hline & 7 & $95(22.7)$ & $96(10.2)$ \\
\hline \multirow{2}{*}{$\begin{array}{l}\text { Self-control for } \\
\text { onychophagia }\end{array}$} & Short-term & $214(52.5)$ & $153(49.4)$ \\
\hline & Long-tern & $194(47.5)$ & $157(50.6)$ \\
\hline \multirow{2}{*}{$\begin{array}{l}\text { Health problems } \\
\text { due to onychophagia }\end{array}$} & No & $336(81.8)$ & $264(84.1)$ \\
\hline & Yes & $75(18.2)$ & $50(15.9)$ \\
\hline \multirow{2}{*}{$\begin{array}{l}\text { Relaxation after biting } \\
\text { nails }\end{array}$} & No & $188(45.9)$ & $264(49.4)$ \\
\hline & Yes & $222(54.1)$ & $270(50.6)$ \\
\hline \multirow{2}{*}{$\begin{array}{l}\text { Thoughts about } \\
\text { setting bad example }\end{array}$} & No & $232(46.2)$ & $403(75.2)$ \\
\hline & Yes & $181(43.8)$ & $133(24.8)$ \\
\hline \multirow{2}{*}{$\begin{array}{l}\text { Thoughts about } \\
\text { negative reactions }\end{array}$} & No & $238(57.9)$ & $349(65.1)$ \\
\hline & Yes & $173(42.1)$ & $187(34.9)$ \\
\hline \multirow{2}{*}{$\begin{array}{l}\text { Thought about } \\
\text { harming reputation }\end{array}$} & No & $233(56.7)$ & $351(65.5)$ \\
\hline & Yes & $178(43.3)$ & $185(34.5)$ \\
\hline \multirow{2}{*}{$\begin{array}{l}\text { Need to hide } \\
\text { onychophagia }\end{array}$} & No & $177(43.4)$ & $301(55.9)$ \\
\hline & Yes & $231(56.6)$ & $237(44.1)$ \\
\hline \multirow{5}{*}{$\begin{array}{l}\text { Situations associated } \\
\text { with onychophagia }\end{array}$} & Anger & $34(8.2)$ & $183(34.3)$ \\
\hline & Stress & $256(61.7)$ & $233(43.7)$ \\
\hline & Hunger & $9(2.2)$ & $2(0.4)$ \\
\hline & Any time & $71(17.1)$ & $67(12.6)$ \\
\hline & Multiple & $45(10.8)$ & $48(9.0)$ \\
\hline \multirow{6}{*}{$\begin{array}{l}\text { Accompanying } \\
\text { behaviors }\end{array}$} & Absent & $987(49.5)$ & $848(57.7)$ \\
\hline & Skin picking & $171(8.6)$ & $179(12.2)$ \\
\hline & Trichotillomania & $68(3.4)$ & $13(0.9)$ \\
\hline & Lip and cheek biting & $483(24.2)$ & 201 (13.7) \\
\hline & Tic disorder & $36(1.8)$ & $34(2.3)$ \\
\hline & Multiple & $248(12.5)$ & $194(13.2)$ \\
\hline
\end{tabular}

Nail-biting and tongue thrusting were the most common ones, and bruxism was the least common (17). In another study, $18 \%$ of children had tongue thrusting, $17 \%$ had mouth breathing, and $3 \%$ had nail-biting (18). A study of children 5 to 13 years old reported that the prevalence of thumb sucking was $25.5 \%$ and lip biting $3 \%$ (19). In our study, onychophagia was not accompanied by any oral habits in most of the students. The most common accompanying oral habit was lip and cheek biting in both university $(24.2 \%)$ and high school students (13.7\%). The differences between studies may originate from differences between the age groups of the study populations. Studies of oral habits have focused on younger children. Larger studies in adolescents and young adults are rare in the literature.

Onychophagia is closely related to stress. One hypothesis suggests that nail-biting acts as a mechanism to relieve stress. It is thought to be a compulsion resulting in damage to the nails. It may be a result of over- or under-stimulation due to factors such as stress, inactivity, or boredom. Onychophagia sufferers sometimes report relaxation or pleasure after nail-biting $(2,16)$. Pacan et al. found that participants with anxiety more commonly described tension before or while trying to resist onychophagia $(65.7 \%)$ and pleasure after nail-biting (42\%) (16). Our study showed that students bite their nails when they felt stressed or angry; it is also stated that they felt relaxed after biting their nails. Thumb sucking and onychophagia are thought to be related to difficulty in the evolution of the oral stage of psychological development due to stress $(2,16)$. Furthermore, in our study students with onychophagia scored higher on perceived stress.

There are conflicting results of studies investigating the relationship between onychophagia, anxiety, and psychiatric disorders $(6,11,16,20)$. Pacan et al. found that $22.5 \%$ of participants with lifetime onychophagia met the criteria of anxiety disorder and 3.1\% of OCD. Although general anxiety disorder was found to correlate with onychophagia, other anxiety disorders and OCD did not correlate (16). Wine et al. reported that pediatric nailbiters (18\%) were diagnosed more commonly with a psychiatric disorder than non-biters (6\%) (9). Similarly, Ghanizadeh et al. found that emotional and behavioral problems were more common in children with onychophagia. They also stated that children with onychophagia had less prosocial ability (11). Leme et al. reported that children and adolescents with deleterious oral habits had more depressive symptoms. They also detected an association between anxiety symptoms and deleterious oral habits (20). In a study evaluating the association between onychophagia and psychiatric disorders in children in a psychiatrically referred sample, attention deficit hyperactivity disorder, oppositional defiant disorder, separation anxiety disorder, enuresis, tic disorder, and OCD were found as the most common associated psychiatric disorders. At least one psychiatric disorder was detected in 56.8\% of the mothers and $45.9 \%$ of the fathers (10). In our study, in university students, the frequency of onychophagia was found to be higher in students with histories of mental disorder and family histories of mental disorder. However, we do not know the current status of the mental health of students because a psychiatric evaluation was not performed.

Table 4 | Scores of Perceived Stress Scale (PSS) and European Health Impact Scale (EUROHISQOL-8) of the students without and with onychophagia.

\begin{tabular}{|c|c|c|c|c|c|c|}
\hline \multirow{3}{*}{ Scale } & \multicolumn{3}{|c|}{ University } & \multicolumn{3}{|c|}{ High school } \\
\hline & \multicolumn{2}{|c|}{ Median (Min-Max) } & \multirow[b]{2}{*}{$p$} & \multicolumn{2}{|c|}{ Median (Min-Max) } & \multirow{2}{*}{$p$} \\
\hline & Without & With & & Without & With & \\
\hline Perceived Stress Scale & $28.0(2-53)$ & $29.0(5-51)$ & 0.001 & $28.2(2-56)$ & $28.0(2-53)$ & 0.863 \\
\hline EUROHISQOL-8 & $28.0(8-40)$ & $26.0(8-40)$ & $<0.001$ & $29.0(8-40)$ & $28.0(8-40)$ & 0.001 \\
\hline
\end{tabular}


Onychophagia may cause stigmatization and affect the quality of life. Pacan et al. found that medical students with onychophagia had significant impairment of quality of life and a higher level of stigmatization (5). Similarly, we found that quality of life was impaired in students with onychophagia. However, most of the students with onychophagia did not believe that this harmed their reputation, set a bad example for others, or caused a negative reaction from people. Whereas most of the university students needed to hide their onychophagia, high school students were not concerned about this.

There are numerous complications of onychophagia. Nail and cuticle problems such as shortening or loss of the nail, onychoschizia, chronic paronychia, infections, pterygium inversum unguis, splinter hemorrhages, melanonychia, and leukonychia can occur (6). Gingival injuries and dental problems such as increased incisal wear and apical root resorption are concerns of dentists related to onychophagia. Oral carriage of intestinal bacteria, Enterobacteriaceae, has been found to be more prevalent in nail-biters (8). In our study, most students denied a history of nail infection and other health problems due to onychophagia. Furthermore, temporomandibular joint problems were reported more common- ly in patients with onychophagia (7), but in our study most of the students did not have jaw pain.

Our study has several limitations. Our findings present the urban population, and so it does not reflect onychophagia in the rural population. The second limitation is that all the data are based on students' own statements. Psychiatric, dermatological, or dental examinations were not performed. Therefore, these data may have inaccuracies due to students' embarrassment or unawareness of their health problems.

\section{Conclusions}

In conclusion, onychophagia is prevalent in the general population, but it is generally hidden or ignored by patients, families, and healthcare providers. It has dermatological, dental, infectious, and psychiatric consequences and comorbidities, and so a multidisciplinary approach is necessary for the prevention and treatment of onychophagia. There are still uncertainties about onychophagia, and so further studies are warranted to clarify and better understand the prevalence, etiopathogenesis, and other features of onychophagia.

\section{References}

1. Halteh P, Scher RK, Lipner SR. Onychophagia: a nail-biting conundrum for physicians. J Dermatolog Treat. 2017;28:166-72.

2. Singal A, Daulatabad D. Nail tic disorders: manifestations, pathogenesis and management. Indian J Dermatol Venereol Leprol. 2017;83:19-26.

3. Tanaka OM, Vitral RW, Tanaka GY, Guerrero AP, Camargo ES. Nailbiting, or onychophagia: a special habit. Am J Orthod Dentofacial Orthop. 2008;134:305-8.

4. Ghanizadeh A. Nail biting: etiology, consequences and management. Iran J Med Sci. 2011;36:73-9.

5. Pacan P, Reich A, Grzesiak M, Szepietowski JC. Onychophagia is associated with impairment of quality of life. Acta Derm Venereol. 2014;94:703-6.

6. Gupta MA, Gupta AK. Self-induced dermatoses: a great imitator. Clin Dermatol. 2019;37:268-77.

7. Motta LJ, Guedes CC, De Santis TO, Fernandes KP, Mesquita-Ferrari RA, Bussadori SK. Association between harmful oral habits and sign and symptoms of temporomandibular joint disorders among adolescents. Oral Health Prev Dent. 2013;11:3-7.

8. Baydaş B, Uslu H, Yavuz I, Ceylan I, Dağsuyu IM. Effect of a chronic nail-biting habit on the oral carriage of Enterobacteriaceae. Oral Microbiol Immunol. 2007; 22:1-4.

9. Winebrake JP, Grover K, Halteh P, Lipner SR. Pediatric onychophagia: a surveybased study of prevalence, etiologies, and co-morbidities. Am J Clin Dermatol. 2018;19:887-91.

10. Ghanizadeh A. Association of nail biting and psychiatric disorders in children and their parents in a psychiatrically referred sample of children. Child Adolesc Psychiatry Ment Health. 2008;2:13.

11. Ghanizadeh A, Shekoohi H. Prevalence of nail biting and its association with mental health in a community sample of children. BMC Res Notes. 2011;4:116.
12. Cohen S, Kamarck T, Mermelstein R. A global measure of perceived stress. J Health Soc Behav. 1983;24:385-96.

13. Eskin M, Harlak H, Demirkıran F, Dereboy C.. The adaptation of the Perceived Stress Scale into Turkish: a reliability and validity analysis. New Symposium J. 2013;51:132-40.

14. Eser E, Lağarlı T, Baydur H, Akkurt V, Akkuş H, Arslan E, et al. Psychometric properties of the Turkish version of the EUROHIS-Tr (WHOQOL-8-Tr) in a Turkish population. Turk J Public Health. 2010;8:136-52.

15. Garde JB, Suryavanshi RK, Jawale BA, Deshmukh V, Dadhe DP, Suryavanshi MK. An epidemiological study to know the prevalence of deleterious oral habits among 6 to 12 year old children. J Int Oral Health. 2014;6:39-43.

16. Pacan P, Grzesiak M, Reich A, Kantorska-Janiec M, Szepietowski JC. Onychophagia and onychotillomania: prevalence, clinical picture and comorbidities. Acta Derm Venereol. 2014;94:67-71.

17. Hegde AM, Xavier AM. Childhood habits: ignorance is not bliss: a prevalence study. Int J Clin Pediatr Dent. 2009;2:26-9.

18. Sharma S, Bansal A, Asopa K. Prevalence of oral habits among eleven to thirteen years old children in Jaipur. Int J Clin Pediatr Dent. 2015;8:208-10.

19. Kharbanda OP, Sidhu SS, Sundaram K, Shukla DK. Oral habits in school going children of Delhi: a prevalence study. J Indian Soc Pedod Prev Dent. 2003; 21:120-4.

20. Leme M, Barbosa T, Castelo P, Gavião MB. Associations between psychological factors and the presence of deleterious oral habits in children and adolescents. J Clin Pediatr Dent. 2014;38:313-7. 